https://doi.org/10.21516/2072-0076-2019-12-4-28-34

\title{
ОАномоментная
}

\section{топографически ориентированная}

фоторефракционная кератэктомия

с ускоренным кросслинкингом

роговичного колмагена в лечении

\section{кератоконуса I сталии}

А.В. Иванова, А.С. Склярова, К.Б. Аетникова, А.Т. Ханцжян, Н.В. Ходжабекян

ФГБУ «НМИЦ глазных болезней им. Гельмгольца» Минздрава России, ул. Садовая-Черногрязская, д. 14/19, Москва, 105062, Россия

Цель работы - оценить эффективность применения одномоментной топографически ориентированной фоторефракционной кератэктомии (ФРК) с ускоренным кросслинкингом роговичного коллагена в лечении пациентов с кератоконусом I стадии. Материал и методы. 38 пациентам (49 глаз) в возрасте от 18 до 44 лет с кератоконусом I стадии проведена одномоментная топографически ориентированная ФРК в сочетании $c$ ускоренным кросслинкингом роговичного коллагена. Кроме стандартного офтальмологического обследования, до и после операции пациентам проводилась аберрометрия, конфокальная микроскопия, оптическая когерентная томография роговицы, исследование на Шеймпфлюг-анализаторе переднего отдела глаза, исследование биомеханических свойств роговицы. Срок наблюдения составил 2 года. Результаты. Некорригированная острота зрения, исходно составлявшая 0,23 \pm 0,03, через 2 года после операции достоверно повысилась до 0,72 \pm 0,02; корригированная острота зрения увеличилась с 0,44 \pm 0,03 до 0,89 \pm 0,02; преломляющая сила роговицы уменьшилась с 45,03 \pm 0,28 до 42,55 \pm 0,31 дптр; показатель сферического компонента рефракции снизился с -2,00 \pm 0,19 до -0,73 \pm 0,09 дптр; показатель иилиндрического компонента рефракции уменьшился

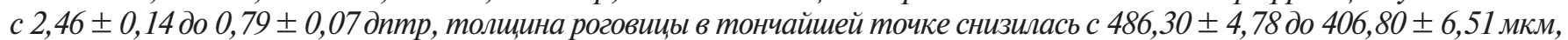
снизились аберрации высшего порядка: показатель Сота - с 0,27 0,12 до 0,08 \pm 0,07, Tilt - c 0,53 \pm 0,11

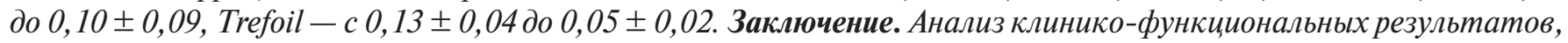
биомеханических свойств и структуры роговицы показал эффективность и безопасность комбинированного лечения пациентов с кератоконусом І стадии.

Ключевые слова: фоторефракционная кератэктомия; кросслинкинг роговичного коллагена; кератоконус; кератотопография

Конфликт интересов: отсутствует.

Прозрачность финансовой деятельности: никто из авторов не имеет финансовой заинтересованности в представленных материалах или методах.

Для цитирования: Иванова А.В., Склярова А.С., Летникова К.Б., Ханджян А.Т., Ходжабекян Н.В. Одномоментная топографически ориентированная фоторефракционная кератэктомия с ускоренным кросслинкингом роговичного коллагена в лечении кератоконуса І стадии. Российский офтальмологический журнал. 2019; 12 (4): 28-34. doi: 10.21516/2072-0076-2019-12-4-28-34 


\section{Simultaneous topography-guided photorefractive keratectomy with accelerated collagen crosslinking in the treatment of stage I keratoconus}

Anastasia V. Ivanova, Anna S. Skliarova, Ksenia B. Letnikova, Anush T. Khandzhyan, Narine V. Khodzhabekyan

Helmholtz National Medical Research Center of Eye Diseases, 14/19, Sadovaya-Chernogryazskaya St., Moscow, 105062, Russia

nastya911@list.ru

Purpose: to evaluate the efficiency of simultaneous topography-guided photorefractive keratectomy (PRK) with accelerated collagen cross-linking in the treatment of stage I keratoconus. Material and methods. 38 patients (49 eyes) aged 18 to 44 with stage I keratoconus were treated with simultaneous topography-guided PRK combined with accelerated corneal collagen crosslinking. Along with standard ophthalmological testing, patients underwent aberrometry, confocal microscopy, optical coherence tomography of the cornea, imaging of the anterior eye section on a Scheimpflug analyzer, and examination of the biomechanical properties of the cornea. The follow-up period was 2 years. Results. Two years after surgery, uncorrected visual acuity which originally was $0.23 \pm 0.03$ showed a statistically significant increase and reached $0.72 \pm 0.02$; best corrected visual acuity improved from $0.44 \pm 0.03$ to $0.89 \pm 0.02$; the refractive power of the cornea fell from $45.03 \pm 0.28$ to $42.55 \pm 0.31 \mathrm{D}$; the spherical component of refraction reduced from $-2.00 \pm 0.19$ to $-0.73 \pm 0.09 \mathrm{D}$; the cylinder component reduced from $2.46 \pm 0.14$ to $0.79 \pm 0.07 \mathrm{~mm}$, the thinnest point of the cornea reduced from $486.30 \pm 4.78$ to $406.80 \pm 6.51 \mu \mathrm{m}$. The highest order aberrations showed the following results: Coma index reduced from $0.27 \pm 0.12$ to $0.08 \pm 0.07$, Tilt reduced from $0.53 \pm 0.11$ to $0.10 \pm 0,09$, and Trefoil reduced from $0.13 \pm 0.04$ to $0.05 \pm 0.02$. Conclusion. The analysis of clinical and functional results, biomechanical properties and structures of the cornea confirmed the efficacy and safety of the combined treatment of patients with stage I keratoconus.

Keywords: photorefractive keratectomy (PRK); corneal collagen crosslinking; keratoconus; keratotopography Conflict of interests: there is no conflict of interests.

Financial disclosure: No author has a financial or property interest in any material or method mentioned.

For citation: Ivanova A.V., Sklyarova A.S., Letnikova K.B., Khandzhyan A.T., Khodzhabekyan N.V. Simultaneous topography-guided photorefractive keratectomy with accelerated collagen cross-linking in the treatment of stage I keratoconus. Russian ophthalmological journal. 2019; 12 (4): 28-34 (in Russian). doi: 10.21516/2072-0076-201912-4-28-34

Кератоконус - хроническое двустороннее дистрофическое заболевание, характеризующееся асимметричным прогрессирующим истончением, растяжением и конусовидным выпячиванием роговицы, помутнением и рубцеванием ее оптической зоны. Следствием этих изменений является оптическая неоднородность роговичной ткани и значительные изменения топографии ее поверхности, сопровождающиеся формированием миопической рефракции глаза и появлением неправильного астигматизма. Изменения, происходящие в структуре и организации роговичного коллагена при кератоконусе, приводят к апоптозу стромальных кератоцитов [1-4].
Современная тактика лечения кератоконуса заключается в последовательном применении медицинских технологий, направленных на стабилизацию патологических изменений роговицы и восстановление остроты зрения [5].

В настоящее время золотым стандартом лечения ранних стадий кератоконуса является кросслинкинг роговичного коллагена, данный метод был предложен в 2003 г. G. Wollensak и соавт. [6]. Кросслинкинг роговичного коллагена представляет собой фотополимеризацию стромальных волокон в результате воздействия на роговицу рибофлавина и ультрафиолетового (УФ) излучения, как следствие, 
формируются дополнительные связи между молекулами роговичного коллагена, повышается механическая прочность роговицы, останавливается прогрессирование кератоконуса [6-9]. Длительность проведения кросслинкинга роговичного коллагена по стандартной методике (около часа) стала причиной поиска возможности ее сокращения за счет увеличения мощности облучения [10]. Остается актуальным также вопрос комбинирования кросслинкинга с поверхностной топографически ориентированной эксимер-лазерной абляцией (фоторефракционная кератэктомия - ФРК) с целью коррекции аметропии и улучшения остроты зрения [11-13].

ЦЕЛЬ работы - оценить эффективность применения одномоментной топографически ориентированной ФРК с ускоренным кросслинкингом роговичного коллагена в лечении пациентов с кератоконусом I стадии на основании анализа клиникофункциональных результатов, биомеханических и морфологических изменений роговицы.

\section{МАТЕРИАЛ И МЕТОДЫ}

В НМИЦ ГБ им. Гельмгольца 38 пациентам (49 глаз) в возрасте от 18 до 44 лет (средний возраст $(\mathrm{M} \pm \mathrm{m})-29,10 \pm 0,58$ года) с кератоконусом I стадии (по классификации М. Amsler) было проведено комбинированное одномоментное хирургическое лечение: I этап - топографически ориентированная фоторефракционная кератэктомия, II этап ускоренный кросслинкинг роговичного коллагена. В исследование вошли пациенты со стабильным кератоконусом, наблюдавшиеся не менее года. Отбор пациентов проводился по следующим критериям: прозрачная роговица (без помутнений и рубцовых изменений), отсутствие сопутствующих инфекционных заболеваний глаз, герпетического кератита и тяжелых аутоиммунных заболеваний в анамнезе, непереносимость коррекции мягкими и жесткими контактными линзами. Толщина роговицы в тончайшей точке после проведения ФРК составляла не менее 350 мкм.

Всем пациентам проводились клинико-функциональные исследования в динамике: до вмешательства и после лечения - через 10 дней, 1, 3, 6, 12 мес и 2 года.

Офтальмологическое обследование включало визометрию, авторефкератометрию, биомикроскопию, офтальмоскопию, исследование на шеймпфлюг-анализаторе Galilei G6 (Ziemer, Швейцария), конфокальную микроскопию (ConfoScan 4, Nidek, Япония), аберрометрию (OPD-scan III, Nidek, Япония), исследование биомеханических свойств роговицы на приборе ORA (Reichert Inc., США), оптическую когерентную томографию роговицы (Spectralis OCT, Heidelberg Engineering, Германия).

Все операции выполнены после получения информированного согласия пациентов.
Іэтап - топографически ориентированная ФРК. Анализ кератотопографических карт и волнового фронта проводился на аберрометре. При оценке аксиальных карт учитывались перепад рефракции в проекции зрачка и разница в оптической силе меридианов с максимальной и минимальной рефракцией. Расчет параметров абляции проводился с помощью программы FinalFit эксимер-лазерной установки NIDEK NAVEX Quest, которая генерирует алгоритм и карту лазерного воздействия для каждого пациента, учитывая все возможные рефракционные аномалии конкретной роговицы.

Под контролем компьютерной программы проводилась поверхностная абляция - фототерапевтическая кератэктомия (ФТК) на глубину 50 мкм в пределах заранее определенной оптической зоны (9,0 мм) с целью деэпителизации роговицы. Далее прицельный луч лазера совмещался со зрительной осью глаза и проводилась персонализированная эксимер-лазерная профилированная абляция (ФРК) в пределах заранее определенной оптической зоны в соответствии с заданными параметрами. Глубина лазерной абляции не превышала 50 мкм. Таким образом, при помощи эксимерного лазера формировалась новая поверхность роговицы.

II этап - кросслинкинг роговичного коллагена. Далее на подготовленную роговицу инстиллировали раствор нормотонического рибофлавина (0,1\% рибофлавин и $20 \%$ декстран) по 1-2 капли каждые 2 мин в течение 30 мин (15 закапываний). Затем настраивали фокусировку излучения (расстояние между излучателем и роговицей пациента - 5 см) и диаметр луча на роговице и выполняли активацию УФ-излучения. Нами использовалась система УФ-излучения ОРТО-Xlink (OPТО, Бразилия) с длиной волны $365 \pm 5$ нм и плотностью излучения 6,366 мВт/см². Доза накопленной энергии составляла 5,347 Дж/см². Одновременно продолжалась инстилляция нормотонического рибофлавина 1-2 капли каждые 2 мин). УФ-облучение продолжалось 14 мин, после чего роговицу промывали физиологическим раствором, закапывали антибактериальный препарат и накладывали мягкую контактную линзу. В послеоперационном периоде назначали инстилляции кортикостероидных, антибактериальных, репаративных и увлажняющих препаратов. Режим стероидной терапии назначался на 80 дней по убывающей схеме.

Статистическая обработка полученных данных проведена на персональном компьютере с использованием приложения Microsoft Excel и пакета статистического анализа Biostatistics 6.0 for Windows (Statsoft Inc., USA). Определяли среднее значение показателя и среднюю квадратичную ошибку $(\mathrm{M} \pm \mathrm{m})$.

\section{РЕЗУЛЬТАТЫ И ОБСУЖДЕНИЕ}

Все операции прошли без осложнений. Полная эпителизация у всех пациентов наблюдалась в сроки от 3 до 5 дней. Ранний послеоперационный 
период сопровождался некоторыми обратимыми осложнениями. В $20 \%$ случаев (10 глаз) отмечался кратковременный отек роговичной ткани, который продолжался первые 2-3 нед после операции и был купирован на фоне стандартной стероидной и репаративной терапии.

Исходные значения некорригированной остроты зрения (НКО3) составили $0,23 \pm 0,03$. Через 10 дней после операции отмечалось статистически достоверное увеличение НКОЗ до 0,55 \pm 0,03 $(\mathrm{p}<0,05)$. В дальнейшем отмечалось постепенное улучшение НКОЗ в течение всего срока наблюдения, через 2 года показатель составил $0,72 \pm 0,02$. Показатель корригированной остроты зрения (KO3) до операции составил 0,44 $\pm 0,03$. Через 10 дней после операции отмечалось статистически достоверное увеличение КО3 до 0,77 $\pm 0,02(\mathrm{p}<0,05)$. В дальнейшем отмечалось плавное улучшение КОЗ в течение всего срока наблюдения, через 2 года показатель равнялся 0,89 $\pm 0,02$ (табл. 1).

Сферический компонент рефракции через 10 дней после операций статистически достоверно уменьшился с $-2,00 \pm 0,19$ до $-0,94 \pm 0,07$ дптр. Затем отмечалось плавное снижение этого показателя в течение всего срока наблюдения, и через 2 года он составил $-0,73 \pm 0,09$ дптр. Через 10 дней после операций отмечалось также статистически значимое снижение цилиндрического компонента рефракции: с 2,46 $\pm 0,14$ до 1,00 $\pm 0,05$ дптр. В дальнейшем наблюдалось постепенное уменьшение астигматического компонента до $0,79 \pm 0,07$ дптр в течение 2 лет после проведения одномоментной топографически ориентированной ФРК в сочетании с ускоренным кросслинкингом роговичного коллагена (табл. 1).

В первые 10 дней отмечалось снижение преломляющей силы роговицы с 45,03 $\pm 0,28$ до 43,62 $\pm 0,27$ дптр ( $<0,05)$, в дальнейшем отмечалось плавное уменьшение этого показателя, который через 2 года составил 42,55 \pm 0,31 дптр (все изменения являлись статистически достоверными). Толщина роговицы в тончайшей точке до операций составляла 486,30 \pm 4,78 мкм. Через 10 дней отмечалось статистически значимое снижение данного показателя до 414,07 \pm 6,38 мкм, что связано с абляцией роговицы и изменением ее структуры. В течение последующего наблюдения отмечалось незначительное колебание толщины роговицы в тончайшей точке: через 3 мес она составляла $412,69 \pm 6,56$ мкм, через 12 мес $-407,20 \pm 6,58$ мкм и через 2 года $-406,80 \pm 6,51$ мкм (все изменения по сравнению с исходным уровнем статистически

Таблица 1. Результаты исследования клинико-функциональных показателей ( $\mathrm{M} \pm \mathrm{m})$

Table 1. Results of clinical and functional studies $(\mathrm{M} \pm \mathrm{m})$

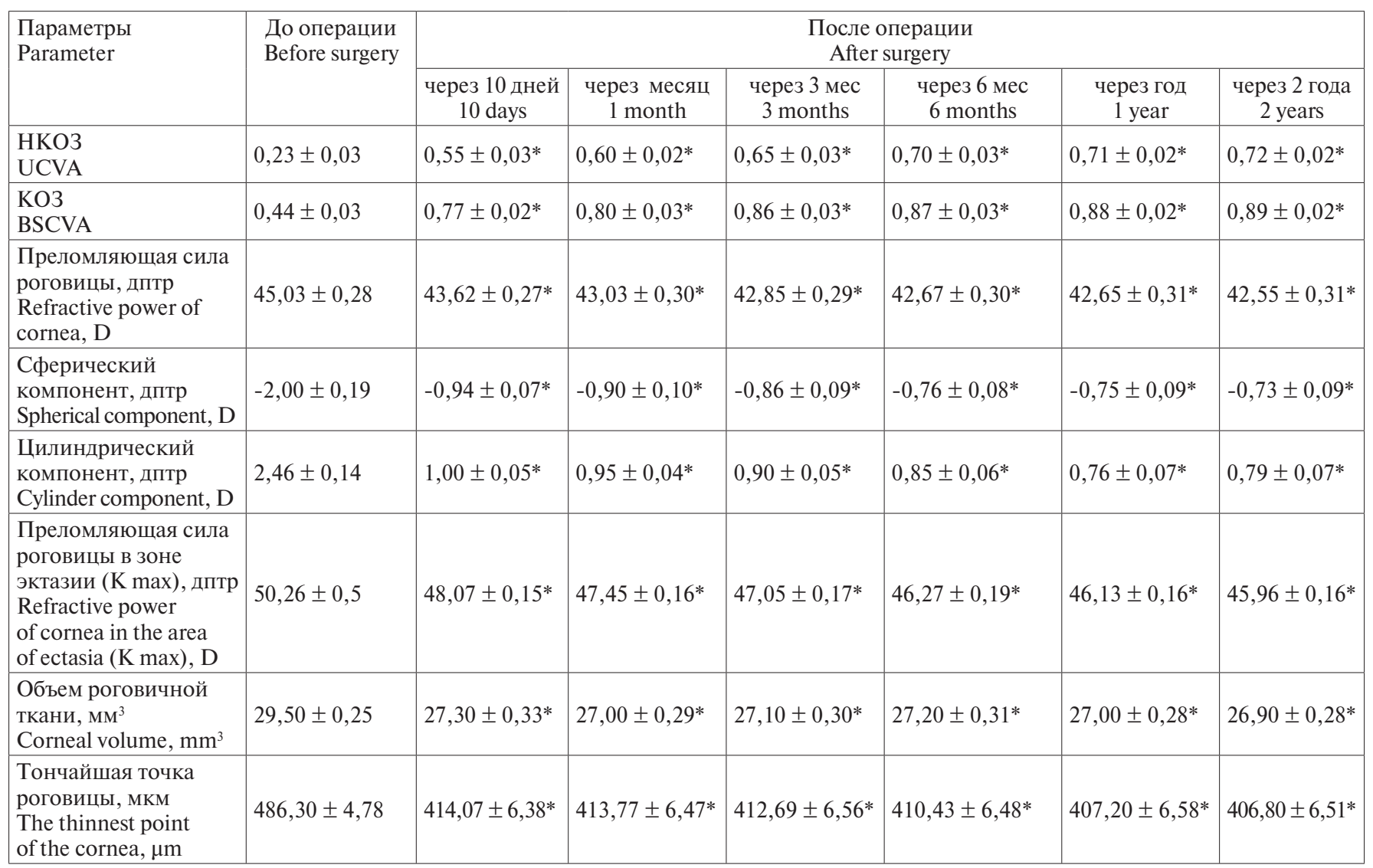

Примечание. ${ }^{*}-\mathrm{p}<0,01$ (сравнение проведено по критерию Стьюдента) - достоверность относительно показателей до лечения. Note. ${ }^{*}-\mathrm{p}<0.01$ (a comparison was made according to Student`s test) - reliability with respect to pretreatment parameters. 
достоверны). Исходный показатель объема рогович-

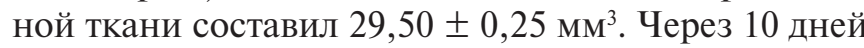
после операций отмечалось статистически значимое снижение этого показателя до 27,30 \pm 0,33 мм³. Через 2 года наблюдений объем роговичной ткани оставался сниженным: 26,90 \pm 0,28 мм³ (см. табл. 1, рис. 1).

Величина корнеального гистерезиса (КГ), которая является индикатором вязкого затухания колебаний в роговичной ткани, через 10 дней после операций незначительно уменьшилась (в результате лазерной абляции роговицы): с 9,15 \pm 0,12 до 8,08 \pm 0,11 мм рт. ст. В течение всего срока наблюдения показатель оставался стабильным и через 2 года составил $8,10 \pm 0,10$ мм рт. ст. Фактор резистентности роговицы (ФРР) через 10 дней после операций статистически значимо снизился с 8,45 $\pm 0,14$ до 7,86 $\pm 0,13$ мм рт. ст., что является результатом эксимер-лазерного воздействия на роговицу. В течение всего срока наблюдений этот показатель оставался стабильным и через 2 года составил 7,89 $\pm 0,11$ мм рт. ст. (табл. 2).

Анализ аберрометрических данных показал статистически достоверное снижение аберраций высшего порядка через 3-4 мес после операции с $0,30 \pm 0,03$ до $0,07 \pm 0,01$. Через 2 года наблюдений среднее значение Сота снизилось с 0,27 $\pm 0,12$ до $0,08 \pm 0,07$, Tilt - с 0,53 \pm 0,11 до $0,10 \pm 0,09$, Trefoil - c 0,13 $\pm 0,04$ до 0,05 $\pm 0,02$ (рис. 2, А, Б).

Метод конфокальной микроскопии дал возможность проанализировать морфологические изменения роговицы после проведения одномоментной топографически ориентированной ФРК в сочетании с ускоренным кросслинкингом роговичного коллагена. Структурные изменения ограничивались передней и средней стромой роговицы (до 290-300 мкм), не затрагивая заднюю часть стромы и эндотелий. Через месяц после воздействия отмечались признаки десквамации поверхностного эпителия, ядра эпителиоцитов становились более контрастными. Выявлялся выраженный полиморфизм клеток базального эпителия и стушеванность их границ. Визуализировались изменения гистиоархитектоники передней и средней стромы роговицы, которая приобретала вид «пчелиных сот». Отмечался апоптоз кератоцитов и исчезновение субэпителиальных и стромальных нервных волокон. Через 3 мес уменьшилось количество гиперрефлективных эпителиоцитов. Границы клеток базального слоя стали более выраженными. Процесс репопулизации кератоцитов начинался примерно через 2-3 мес после процедуры и полностью завершался в течение года. К 6-му месяцу после проведения операций

Рис. 1. Кератотопографический и аберрометрический анализ до и после операции

Fig. 1. Keratotopographic and aberrometric analysis before and after surgery

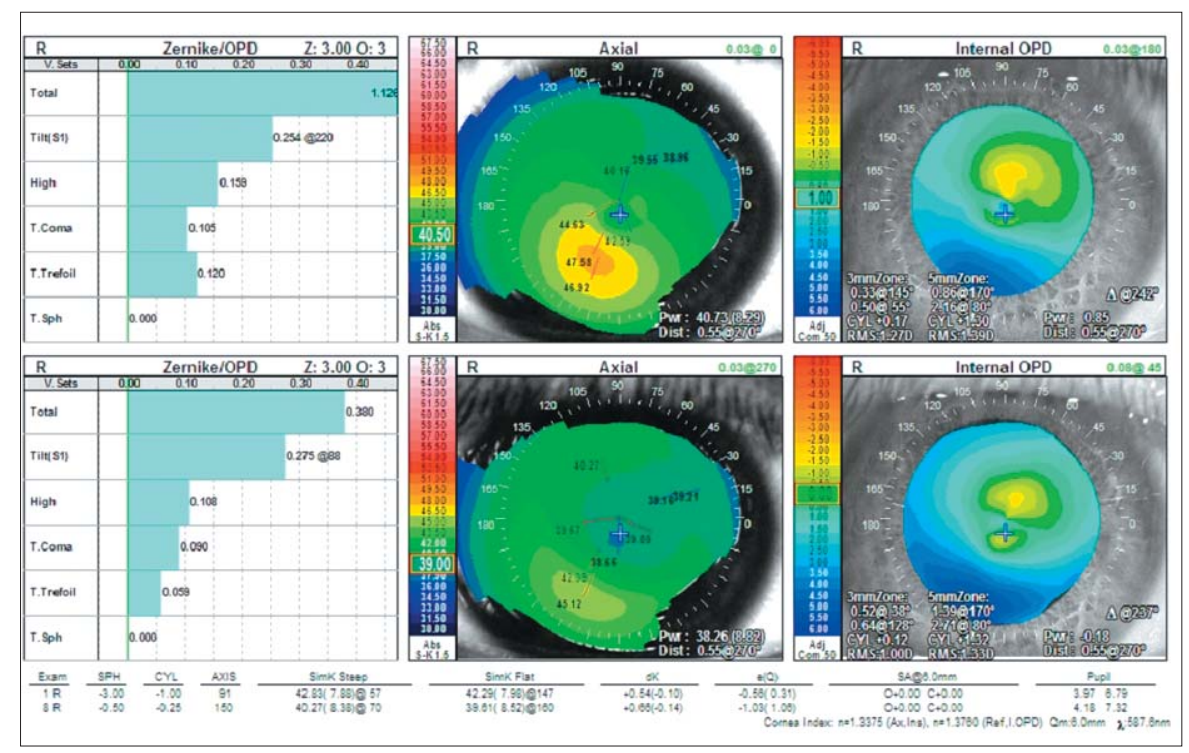

Таблица 2. Значения корнеального гистерезиса (КГ) и фактора резистентности роговицы (ФРР) до и после лечения (М $\pm \mathrm{m})$ Table 2. Meanings of corneal hysteresis $(\mathrm{CH})$, corneal resistance factor $(\mathrm{CRF})$ before and after treatment $(\mathrm{M} \pm \mathrm{m})$

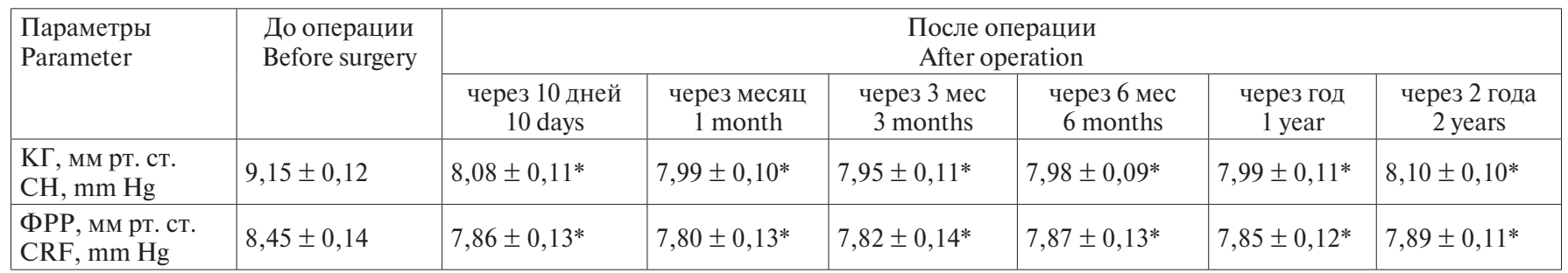

Примечание. * - различия показателей до и после операции статистически достоверны, $\mathrm{p}<0,01$.

Note. ${ }^{*}$ - the differences before and after surgery are statistically significant, $\mathrm{p}<0.01$. 


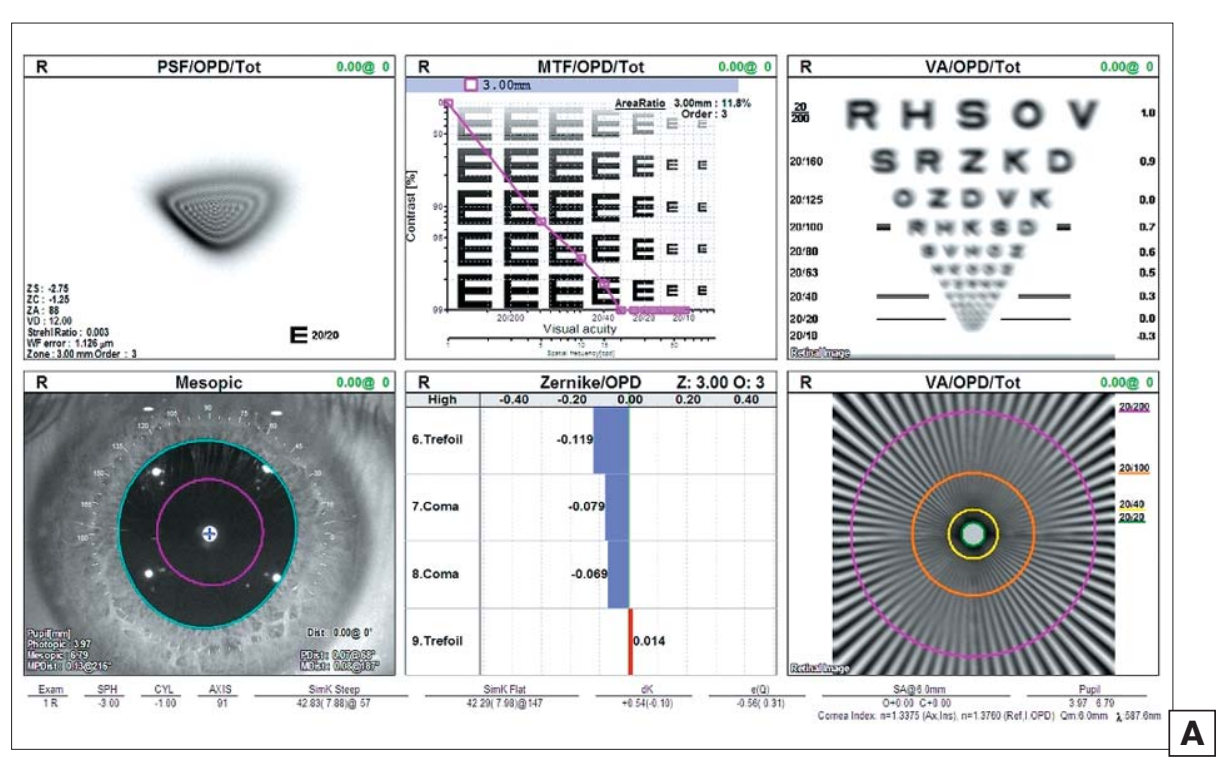

Рис. 2. Показатели качества зрения. А до лечения. Б - после лечения

Fig. 2. Optical quality. A - before treatment. 5 - after treatment

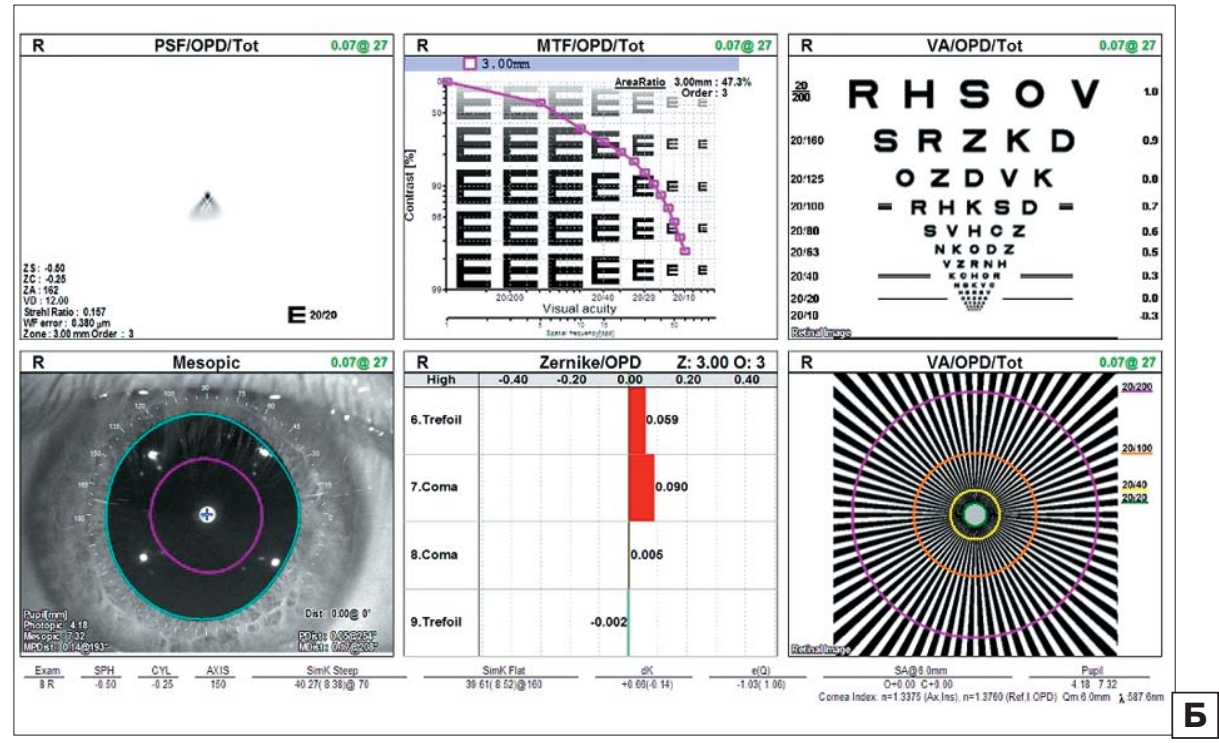

визуализировалась регенерация субэпителиальных и стромальных нервных волокон в передней строме, наблюдалось восстановление популяции кератоцитов, увеличение плотности экстрацеллюлярного матрикса и появление складчатости за счет эффекта «сшивания». Стойкий эффект «сшивания» сохранялся на протяжении 2 лет наблюдений.

Таким образом, проведенные нами клиникофункциональные исследования показали эффективность и безопасность применения одномоментной топографически ориентированной ФРК в сочетании с ускоренным кросслинкингом роговичного коллагена в лечении пациентов с кератоконусом I стадии. Снижение показателей офтальмометрии, сферического и цилиндрического компонентов рефракции, аберраций высшего порядка, повышение остроты зрения свидетельствуют об улучшении оптических свойств роговицы. Стабильные показатели КГ и ФРР, значительные структурные изменения роговицы (стойкий эффект «сшивания») свидетельствуют о биомеханической стабилизации кератоконуса.

\section{ЗАКЛЮЧЕНИЕ}

Одномоментная топографически ориентированная ФРК в сочетании с ускоренным кросслинкингом роговичного коллагена в лечении пациентов с кератоконусом I стадии обеспечивает безопасное и эффективное моделирование формы роговицы за счет уменьшения зоны ее иррегулярности, улучшает зрительные функции и оказывает стабилизирующий эффект.

\section{Лumepamypa/References}

1. Горскова Е.Н., Севостьянов Е.Н., Гиниатуллин Р.У. идр. Апоптоз кератоцитов при кератоконусе. Вестник офтальмологии. 2002; 4: 36-8.

Gorskova E.N., Sevostianov E.N., Giniatullin R.U., et al. Apoptosis of keratocytes in kertoconus. Vestnik oftal'mologii. 2002; 4: 36-8 (in Russian).

2. Дронов M.M. Диагностика первичного переднего кератоконуса. Офтальмохирургия и терапия. 2004; 3: 2-7.

Dronov M.M. Diagnostics of primary anterior kertoconus. Oftal'mokhirurgija i terapija. 2004; 3: 2-7 (in Russian).

3. Sherwin T., Brookes N.H. Morphological changes in keratoconus: Pathology or pathogenesis. Clin. Exp. Ophthalmol. 2004; 32: 211-7. doi: $10.1111 /$ j.1442-9071.2004.00805.x 
4. Rabinowitz Y.S. Definition, etiology and diagnosis of keratoconus. Highlights of Ophthalmology, International Edition. 2004; 21: 241-60.

5. Pietrini D., Tony Guedj T. Strategy for boosting visual acuity in keratoconus patients. J. Cataract Refract. Surg. Today, 2012 Febr.; 32-4.

6. Wollensak G., Spoerl E., Seiler T. Riboflavin/Ultraviolet-A Induced Collagen Crosslinking for the Treatment of Keratoconus. Am. J. Ophthalmol. 2003; 135 (5): 620-7. doi:10.1016/s0002-9394(02)02220-1

7. Boxer Wachler B.S. Corneal Collagen Crosslinking with Riboflavin. Cataract and Refract. Surg. Today. 2005 Jan.; 1: 73-4.

8. Wollensak $G$. Crosslinking treatment for progressive keratoconus: new hope. Curr. Opin. Ophthalmol. 2006; 17 (4): 356-60. doi: 10.1097/01.icu.0000233954.86723.25

9. Wollensak G., Iomdina E. Biomechanical and histological changes after corneal crosslinking with and without epithelial debridement. J. Cataract Refract. Surg. 2009; 35 (3): 540-6. doi: 10.1016/j. jcrs.2008.11.036

Поступила: 18.04.2019

Переработана: 01.06.2019

Принята к печати: 30.08.2019
10. Kymionis G., Kontadakis G., Hashemi K. Accelerated versus conventional corneal crosslinking for refractive instability: an update. Curr. Opin. Ophthalmol. 2017; 28: 343-7. doi: 10.1097/ ICU.0000000000000375

11. Kanellopoulos $J$. Comparison of sequential vs same-day simultaneous collagen cross linking and topography-guided PRK for treatment of keratoconus. J. Refract. Surg. 2009; 25: 812-8. doi: 10.3928/1081597X-20090813-10

12. Kanellopoulos A., Binder P.S. Collagen cross-linking (CCL) with sequential topography guided PRK: a temporizing alternative for keratoconus to penetrating keratoplasty. Cornea. 2007; 26: 891-5. doi:10.1097/ICO.0b013e318074e424

13. Kymionis G.D., Grentzelos M.A., Portaliou D.M., et al. Corneal collagen crosslinking (CXL) combined with refractive procedures for the treatment of corneal ectatic disorders: CXL-Plus. J. Refract. Surg. 2014; 3: 566-76. doi: 10.3928/1081597X20140711-10

Originally received: 18.04 .2019

Final revision: 01.06 .2019

Accepted: 30.08 .2019

\section{ИНФОРМАЦИЯ ОБ АВТОРАХ/INFORMATION ABOUT THE AUTHORS}

ФГБУ «НМИЦ глазных болезней им. Гельмгольца» Минздрава России, ул. Садовая-Черногрязская, д. 14/19, Москва, 105062, Россия

Анастасия Владимировна Иванова, канд. мед. наук, научный сотрудник отдела патологии рефракции, бинокулярного зрения и офтальмоэргономики

Анна Сергеевна Склярова, канд. мед. наук, врачофтальмолог отдела патологии сетчатки и зрительного нерва

Ксения Борисовна Летникова, канд. мед. наук, научный сотрудник отдела патологии сетчатки и зрительного нерва

Ануш Тиграновна Ханджян, канд. мед. наук, старший научный сотрудник отдела патологии сетчатки и зрительного нерва

Нарине Володяевна Ходжабекян, канд. мед. наук, ведущий научный сотрудник отдела патологии рефракции, бинокулярного зрения и офтальмоэргономики Для контактов: Анастасия Владимировна Иванова, nastya911@list.ru
Helmholtz National Medical Research Center of Eye Diseases, 14/19, Sadovaya-Chernogryazskaya St., Moscow, 105062, Russia

Anastasia V. Ivanova, Cand. of Med. Sci., researcher, department of refraction pathology, binocular vision and ophthalmoergonomics

Anna S. Skliarova, Cand. of Med. Sci., ophthalmologist, department of pathology of retina and optic nerve

Ksenia B. Letnikova, Cand. of Med. Sci., researcher, department of pathology of retina and optic nerve

Anush T. Khandzhyan, Cand. of Med. Sci., senior researcher, department of pathology of retina and optic nerve

Narine V. Khodzhabekyan, Cand. of Med. Sci., leading researcher, department of refraction pathology, binocular vision and ophthalmoergonomics

Contact information: Anastasia V. Ivanova, nastya911@list.ru 